\title{
Ameliorative effect of Leflunomide on lung injury following an aspiration
}

\author{
Yilmaz MZ1 ${ }^{1}$, Torun AC ${ }^{1}$, Guzel A2 ${ }^{2}$, Murat $N^{3}$, Okuyucu A ${ }^{4}$, Yilmaz N ${ }^{5}$, Gacar A ${ }^{6}$, Guvenc $T^{6}$, Guzel A \\ Ondokuz Mayis University, Faculty of Dentistry, Department of Pedodontia, Samsun, Turkey. \\ drziyilmaz@gmail.com
}

\begin{abstract}
Background: We aimed to investigate the therapeutic effectiveness of leflunomide (LEF) in lung injury after an aspiration of unknown pathophysiology.

Material and methods: Forty-two healthy Sprague Dawley rats were anesthetized and allocated to six experimental groups: saline (S) aspirated, S+LEF, hydrochloric acid ( $\mathrm{HCl}$ ) aspirated, $\mathrm{HCl}+\mathrm{LEF}$, formula aspirated (FOR), and FOR+LEF. The treatment groups (S+LEF, HCl+LEF, and FOR+LEF) received $20 \mathrm{mg} / \mathrm{kg} /$ day intraperitoneal (i.p.) injection of LEF for seven days. At the end of the seven days, blood and tissue samples were taken from the rats for histopathological, biochemical, and immunohistochemical examination.

Results: There was a significant increase in serum levels of $\mathrm{YKL}-40$, a chitinase-like protein, in the $\mathrm{HCl}$ group after the aspiration $(p<0.01)$. The increase in serum YKL-40 levels decreased significantly with LEF treatment $(p<0.01)$. There was no significant difference in serum YKL-40 levels in the FOR group compared to the control group at pretreatment and in the FOR+LEF group at post-treatment. There was a significant increase in serum thiobarbituric acid-reactive species (TBARS) values in the $\mathrm{HCl}$ and $\mathrm{FOR}$ groups compared to the control group $(p=0.001$ and $p<0.01$, respectively). In both treatment groups, the serum TBARS values significantly decreased after treatment with LEF $(p=0.001$ and $p<0.05$, respectively). There was a significant improvement in the histopathological scores, which deteriorated after the aspiration, and in the number of inducible nitric oxide synthase (iNOS)-positive cells after treatment with LEF.

Conclusions: LEF can be a useful agent in the treatment of gastric content aspiration-induced acute lung injury (ALI) (Tab. 1, Fig. 5, Ref. 43). Text in PDF www.elis.sk.

Key words: aspiration, lung injury, Leflunomide, iNOS, oxidative markers.
\end{abstract}

\section{Introduction}

Foreign substances taken into the lungs through inhalation are described as aspiration. Aspiration pneumonitis (AP) refers to the inhalation of sterile gastric contents due to acute chemical lung injury induced by a noninfectious inflammatory response (1). Aspiration of acidic gastric content is a serious aspiration syndrome, with mortality rates up to $30-70 \%$ (2). Changes in the level of consciousness, neuromuscular and gastrointestinal diseases, and diseases requiring intubation in the intensive care unit increase the risk of aspiration (3). In anesthesia practice, surgery is a predisposing factor for the development of AP in preoperative and postoperative periods. Thus, developing diagnostic and

${ }^{1}$ Ondokuz Mayis University, Faculty of Dentistry, Department of Pedodontia, Samsun, Turkey, ${ }^{2}$ Ondokuz Mayis University, Faculty of Medicine, Department of Chest Disease, Samsun, Turkey, ${ }^{3}$ Ondokuz Mayis University, Faculty of Engineering, Industrial Engineering, Samsun, Turkey, ${ }^{4}$ Ondokuz Mayis University, Faculty of Medicine, Department of Medical Biochemistry, Samsun, Turkey, ${ }^{5}$ Ondokuz Mayis University, Faculty of Medicine, Department of Anesthesiology, Samsun, Turkey, ${ }^{6}$ Ondokuz Mayis University, Faculty of Veterinary Medicine, Department of Pathology, Samsun, Turkey, and ${ }^{7}$ Ondokuz Mayis University, Faculty of Medicine, Department of Pediatrics, Samsun, Turkey

Address for correspondence: M.Z. YILMAZ, MD, Ondokuz Mayis University, Faculty of Dentistry, Department of Pedodontia, Samsun, Turkey. Phone: $+90.362 .3121919 / 4077$ treatment modalities for AP is very important in the practice of anesthesia.

Most cases of chemical aspiration proceed to acute lung injury (ALI) and acute respiratory distress syndrome (ARDS), with a high rate of morbidity and mortality and end-organ damage due to hypoxia (4). Factors contributing to hypoxemia include pulmonary edema, decreased surfactant activity, reflex airway closure, alveolar hemorrhage, and hyaline membrane formation (5). Increases in inflammation-induced free oxygen radicals cause additional damage by oxidation of cellular components such as lipids, proteins, and DNA. The most important damage is caused by lipid peroxidation, which results in distortion of the cell membrane function and structure. Malondialdehyde (MDA), the end product of lipid degradation, is considered to be an indirect indicator of lipid peroxidation. Levels of MDA are determined in blood by measurement of biochemical thiobarbituric acid reactive species (TBARS) (6).

Nitric oxide (NO), used as a signaling molecule in intracellular physiological and pathological processes, reacts with the increased levels of superoxide radicals induced by inflammation and forms peroxynitrite, which is a more potent oxidant $(7,8)$. As shown in many studies, levels of NO, produced by inducible NO synthase (iNOS), and iNOS in tissues and blood can be used to detect oxidation in inflammatory processes (9-11).

In recent years, many studies have investigated biomarkers that could be used in the diagnosis and monitoring of diseases, 


\section{7-183}

that are easy to use, and that provide more accurate results when measured in serum and tissues. Studies showed that YKL-40, a chitinase-like protein, was increased in serum and tissue, especially in chest diseases accompanied by inflammation, infection, and remodeling, such as asthma, chronic obstructive pulmonary disease, cystic fibrosis, and pleural effusion (12-15). They also showed that YKL-40 Can be used as a biomarker for monitoring the severity of these diseases (12-15).

Leflunomide (LEF) is an effective drug used in the treatment of many diseases, particularly rheumatic conditions, due to its anti-inflammatory, antiproliferative, and immunosuppressive effects (16). It also has therapeutic uses in many other diseases due to its ability to protect against oxidative damage and its antifibrotic properties (20). It acts by inhibiting dihidro-orotate dehydrogenase and protein tyrosine kinase enzymes, which are important in the immune response (16-18).

In this study, we examined the therapeutic efficacy of LEF in lung injury caused by gastric aspiration, which is a particularly significant problem in the intensive care units, using oxidative markers to investigate the relationship between serum YKL-40 and the severity of damage in ALI due to pulmonary aspiration.

\section{Materials and methods}

\section{Experimental protocol and animals}

This study was approved by the Experimental Animal Studies Ethics Committee of Ondokuz Mayis University, Samsun, Turkey. A total of 42 healthy female Sprague Dawley rats weighing 250-300 g were enrolled in this study and provided by the Experimental Research Center of the medical faculty of Ondokuz Mayis University. All the rats were maintained in windowless animal quarters at a temperature of $24{ }^{\circ} \mathrm{C}$ and humidity of

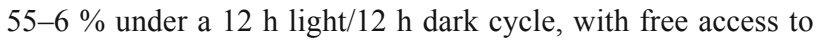
food and water.

The rats were anesthetized with an intraperitoneal (i.p.) injection of ketamine hydrochloride $(100 \mathrm{mg} / \mathrm{kg})$ and xylazine (10 $\mathrm{mg} / \mathrm{kg}$ ). They were allowed to breathe spontaneously during the surgical procedure. After a neck incision, a direct puncture with a 21-gauge needle was performed 2-4 tracheal rings below the larynx, and saline, hydrochloric acid ( $\mathrm{HCl}$ ), and formula (FOR) were injected into the larynx at a volume of $1 \mathrm{ml} / \mathrm{kg}$. All the rats were allocated to six experimental groups: saline (S) aspirated, S+LEF, $\mathrm{HCl}(0.1 \mathrm{M}, \mathrm{pH} 1.25)$ aspirated, $\mathrm{HCl}+\mathrm{LEF}, \mathrm{FOR}$ aspirated (Ensure ${ }^{\circledR}$ Nutrition Shake, Abbott Nutrition), and FOR+LEF. Each group contained seven animals. After administration, the incision was repaired with a 6-0 ethilon suture.
After seven days of treatment of the S+LEF, $\mathrm{HCl}+\mathrm{LEF}$, and FOR+LEF groups with $20 \mathrm{mg} / \mathrm{kg}$ /day i.p. injection of LEF (19), all the rats were killed with an i.p. injection of ketamine hydrochloride and $10 \mathrm{mg} / \mathrm{kg}$ of xylazine. To obtain a sample of lung tissue, lungs were removed with bilateral anterior thoracotomy and median sternotomy after euthanasia. Samples were taken from both lungs for histopathological and immunohistochemical examination. Bloods samples were acquired from the hearts.

\section{Histopathological studies}

Immunohistochemical and histopathological analyses of the lung tissue samples were conducted to determine the effects of aspiration and treatment with LEF. The lungs were rapidly excised and fixed in $10 \%$ buffered formalin for $24-72 \mathrm{~h}$ and embedded in paraffin as per routine procedures. Sections $5 \mu \mathrm{m}$ thick were prepared from the blocks and stained with hematoxylin eosin for routine microscopic examination. A histopathological evaluation was performed in at least eight randomly selected microscopic high-power fields from each tissue sample. Subsequently, all slides were examined by a pathologist blinded to the study groups, and they scored all the microscopic slides according to the degree of peribronchial inflammatory cell infiltration (PICI), alveolar septal infiltration (ASI), alveolar edema (AED), alveolar exudate (AEX), and alveolar histiocytes (AHI) using the 4-point scale developed by Takil et al (Tab. 1) (20).

\section{Immunohistochemistry procedure (LEF, aspiration pneumonia)}

The lung tissue samples were fixed in $10 \%$ neutral buffered formalin and embedded in paraffin. All the samples were sectioned at a thickness of $5 \mu \mathrm{m}$, deparaffinized, and rehydrated. The streptavidin-biotin-peroxidase complex technique (Histostain Plus Kit; Zymed, cat no: 85-8943, CA, USA) was used for the immunohistochemical study. Endogenous peroxidase activity was removed by incubation with $2 \%$ hydrogen peroxidase in methanol for $30 \mathrm{~min}$ at room temperature. Antigen retrieval was performed by microwave treatment for $15 \mathrm{~min}$ in citrate buffer $(\mathrm{pH} 6.0)$. Rabbit polyclonal anti-inducible iNOS antibody (1/250; Abcam, cat no: ab3523, UK) was used as the primary antibody. Aminoethylcarbazole was used as the chromogen in $\mathrm{H} 2 \mathrm{O} 2$ for $10 \mathrm{~min}$. The sections were counterstained with Lillie Mayer's hematoxylin for $1 \mathrm{~min}$ and rinsed with tap water. Subsequently, the sections were mounted with an aqueous mounting medium. Immunohistochemical iNOS staining of the lung tissue slides were evaluated semiquantitatively according to the intensity of the differences between each experimental group. The staining intensity of iNOS was recorded as faint $(-/+)$, mild $(+)$, moderate $(++)$, and strong

Tab. 1. The 4-point scale used for histopathologic assessment.

\begin{tabular}{|c|c|c|c|c|}
\hline & 0 & 1 & 2 & 3 \\
\hline PICI & No & Prominent germinal centers of lymphoid follicules & Infiltration between lymphoid follicules & Confluent bandlike form \\
\hline ASI & No & Minimal & Moderate & Severe, impending of lumen \\
\hline AED & No & Focal & In multiple alveoli & Widespread, Involving lobules \\
\hline AEX & No & Focal & In multiple alveoli & Prominent, widesp \\
\hline AHI & No & Scattered ina few alveoli & Forming clusters in alveolar spaces & Filling the alveolar spaces \\
\hline
\end{tabular}

terstitial fibrosis; GRA - Granuloma; NEC - Necrosis. 
$(+++)$. The evaluation of the immunostaining was performed in at least eight randomly selected areas per lung section, using two sections from each animal at $400 \times$ magnification. The final score calculated in each category for each individual rat was the mean of the scores from the sections of the lungs examined.

\section{Biochemical evaluation}

The blood samples were transferred to tubes without anticoagulant after the rats were sacrificed. The blood was incubated for $30 \mathrm{~min}$ at room temperature to allow clotting. Then, serum was obtained by centrifuging at $40{ }^{\circ} \mathrm{C}, 3000 \mathrm{~g}$ for $10 \mathrm{~min}$. The supernatant was stored at $-80{ }^{\circ} \mathrm{C}$ in another tube until the study was made. All the samples were dissolved at $2-80 \mathrm{C}$ for one day prior to the biochemical analysis.

The TBARS levels in the serum samples were measured with a TBARS assay kit (10009055, Cayman Chemical Company, Ann Arbor, MI, USA) in accordance with the procedures specified by the manufacturer. Malondialdehyde (MDA)-TBA products that formed in this assay, which are based on the reaction of MDA with TBA in an acidic environment, were measured colorimetrically at $540 \mathrm{~nm}$. Test results were given as $\mathrm{mmol} / \mathrm{L}$.

Chitinase 3-like-1 (YKL-40) levels in one of the serum samples was measured with a YKL-40 ELISA kit (CK-E90203, Hangzhou Eastbiopharm Co. Ltd., Hangzhou, China) in accordance with the procedures of the manufacturer. The results of this test, run in conjunction with the sandwich ELISA method, in which a doubleantibody was used, were given in $\mathrm{ng} / \mathrm{ml}$.

\section{Statistical methods}

All the histopathological and biochemical parameters were analyzed with the SPSS 21.0 package software for Windows. The biochemical measurements are shown as the mean $( \pm)$ standard deviation (SD). The histopathological scores are presented as the median (min-max). All the measurements and scores were compared to Mann-Whitney U tests. The $p$ value of $<0.05$ was considered statistically significant.

\section{Results}

\section{Biochemical findings}

Serum YKL-40 levels

There was no statistically significant change in the serum YKL40 levels between the sham $(18.33 \pm 3.56 \mathrm{ng} / \mathrm{ml})$ and the $\mathrm{S}+\mathrm{LEF}$ groups $(18.74 \pm 0.64 \mathrm{ng} / \mathrm{ml})(\mathrm{p}>0.05)$. Serum YKL-40 levels were significantly higher in the $\mathrm{HCl}$ group $(32.61 \pm 8.19 \mathrm{ng} / \mathrm{ml})$ than in the sham group $(\mathrm{p}<0.01)$, but there was no statistically significant difference in the serum YKL-40 levels between the FOR $(24.81 \pm$ $9.41 \mathrm{ng} / \mathrm{ml}$ ) and sham groups ( $\mathrm{p}>0.05$ ) (Fig. 1).

After the LEF treatment, serum YKL-40 levels were decreased in the $\mathrm{HCl}+\mathrm{LEF}$ group $(20.35 \pm 3.13 \mathrm{ng} / \mathrm{ml})$ compared to the $\mathrm{HCl}$ group $(\mathrm{p}<0.01)$. There was no statistically significant change in the serum YKL-40 levels in the FOR+LEF group $(19.15 \pm 2.0 \mathrm{ng} /$ $\mathrm{ml})$ compared to the FOR group $(\mathrm{p}>0.05)$ (Fig. 1) in response to the LEF treatment.

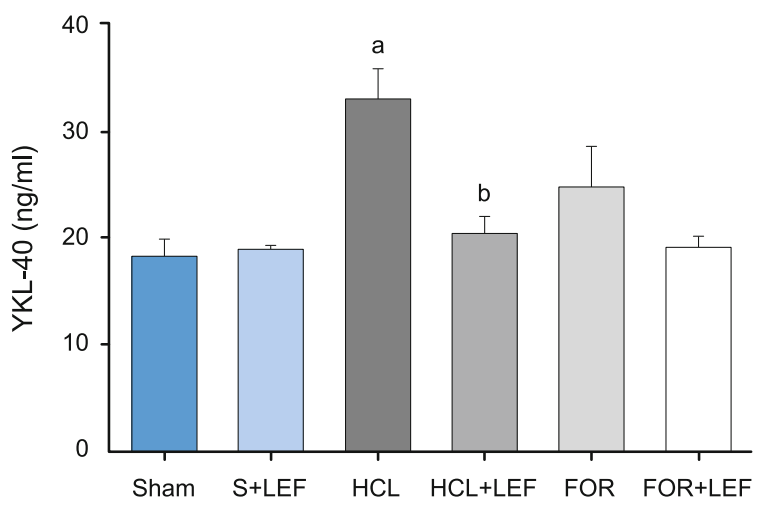

Fig. 1. Serum YKL-40 levels in all study groups were expressed. a $\mathrm{p}<0.01$ compared to Sham group; $\mathrm{b}-\mathrm{p}<0.01$ compared to HCL group. Sham (S); Normal saline aspirated, $S+L E F ; S$ group treated with Leflunomide, $\mathrm{HCl}$; Hydrochloric acid aspirated, $\mathrm{HCl}+\mathrm{LEF}$; HCl group treated with Leflunomide, FOR; Formula aspirated, FOR+LEF; FOR group treated with Leflunomide.

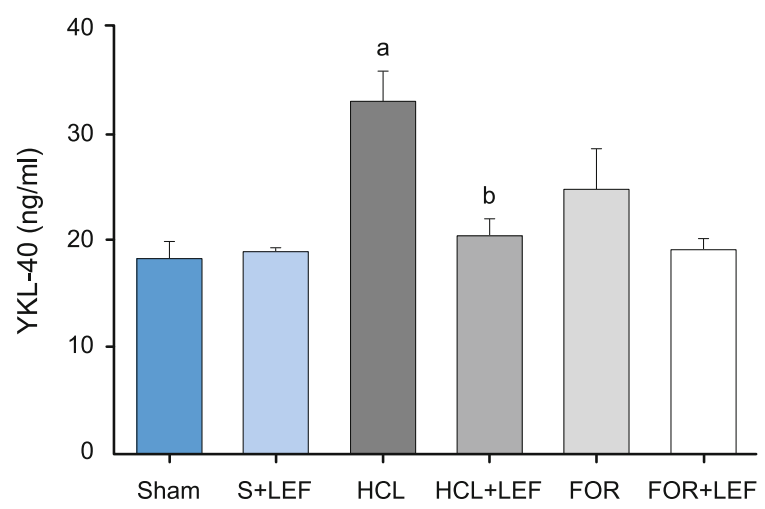

Fig. 1. Serum YKL-40 levels in all study groups were expressed. a $\mathrm{p}<0.01$ compared to Sham group; $\mathrm{b}-\mathbf{p}<0.01$ compared to HCL group. Sham (S); Normal saline aspirated, $S+L E F ; S$ group treated with Leflunomide, $\mathrm{HCl}$; Hydrochloric acid aspirated, $\mathrm{HCl}+\mathrm{LEF}$; HCl group treated with Leflunomide, FOR; Formula aspirated, FOR+LEF; FOR group treated with Leflunomide.

\section{Serum TBARS levels}

There was no statistically significant difference in the serum TBARS levels between the sham $(6.85 \pm 1.37 \mu \mathrm{mol} / \mathrm{L})$ and the $\mathrm{S}+\mathrm{LEF}$ groups $(7.43 \pm 1.09 \mu \mathrm{mol} / \mathrm{L})(\mathrm{p}>0.05)$. Serum TBARS levels were significantly higher in the $\mathrm{HCl}(19.94 \pm 5.22 \mu \mathrm{mol} / \mathrm{L})$ and FOR $(17.88 \pm 7.33 \mu \mathrm{mol} / \mathrm{L})$ groups than in the sham group ( $p=0.001$ and $p<0.01$, respectively) (Fig. 2).

The serum TBARS levels in the $\mathrm{HCl}+\mathrm{LEF}$ group $(7.32 \pm 0.69$ $\mu \mathrm{mol} / \mathrm{L})$ were statistically lower than in the $\mathrm{HCl}$ group $(\mathrm{p}=0.001)$. In contrast, the serum TBARS levels in the FOR+LEF group (7.56 $\pm 0.64 \mu \mathrm{mol} / \mathrm{L}$ ) were statistically lower compared to those in the FOR group $(\mathrm{p}<0.05)$ (Fig. 2).

\section{Histopathological results}

The histopathological scores in the study groups are shown in the Figure 3. In the $\mathrm{HCl}$ group, $\mathrm{PICI}$ and lymphoid follicles were 

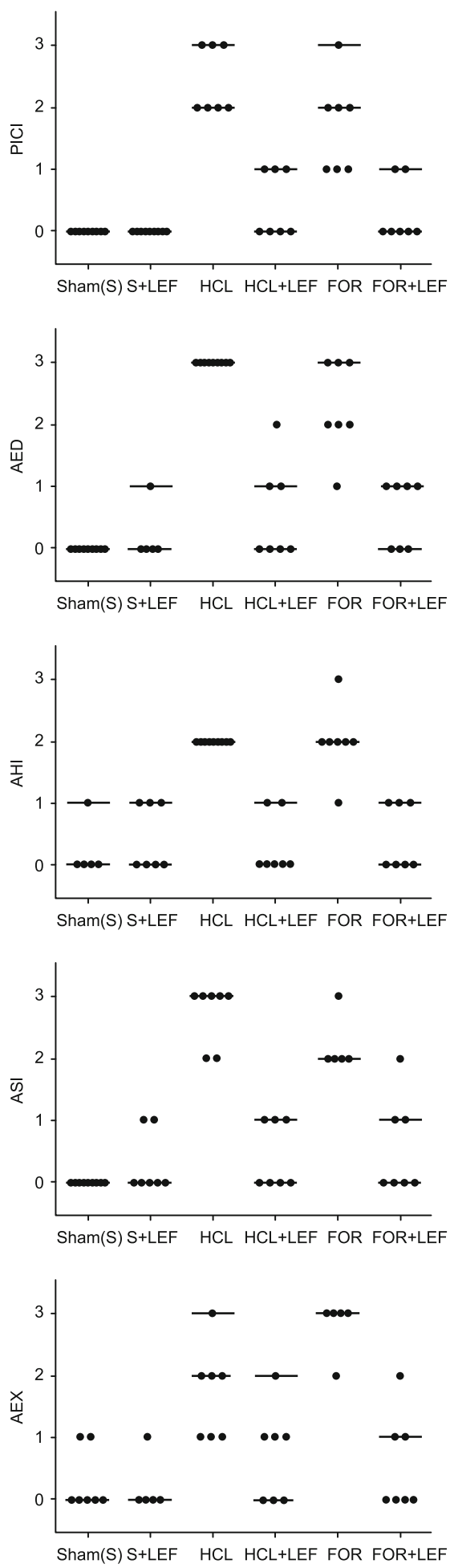

Fig. 3. All histopathological 4-point scale scores of all study groups were represented. Peribronchial inflammatory cell infiltration (PICI); Alveolar septal infiltration (ASI); Alveolar edema (AED); Alveolar exudate (AEX); Alveolar histiocytes (AHI). Sham (S); Normal saline aspirated, $\mathrm{S}+\mathrm{LEF}$; $\mathrm{S}$ group treated with Leflunomide, $\mathrm{HCl}$; $\mathrm{Hydrochloric}$ acid aspirated, $\mathrm{HCl}+\mathrm{LEF}$; HCl group treated with Leflunomide, FOR; Formula aspirated, FOR+LEF; FOR group treated with Leflunomide.

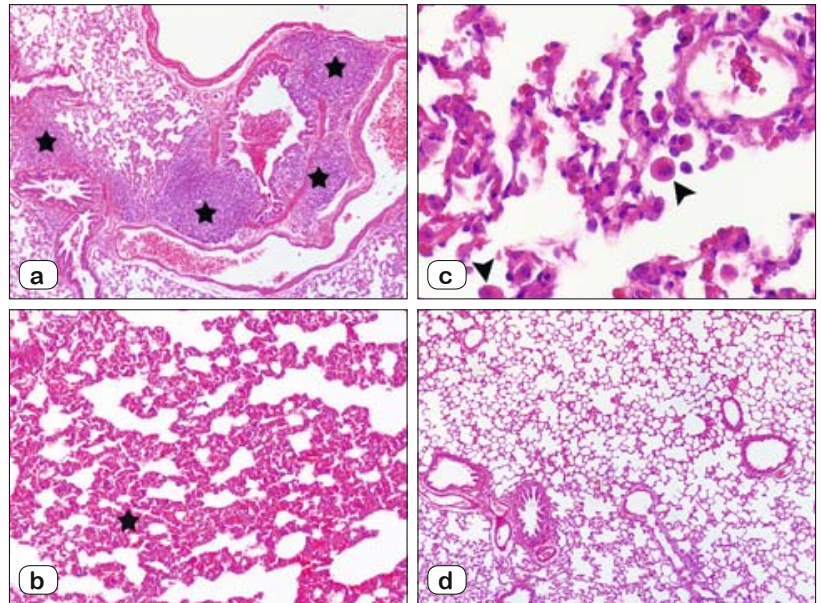

Fig. 4. Histopathological evaluation of lung tissues in study groups were represented. a - Peribronchial inflamatory cell infiltration, showing infiltration between lymphoid follicules (star) in HCL group, HE x4, b-Moderate alveolar septal infiltration (star) in FOR group, HEx10, - Multivacuolated alveolar histiocytes in alveolar space (arrow heads), FOR+LEF group, HEx40, d - There is no peribronchial and interstitial cell infiltration in Sham group, HEx4.
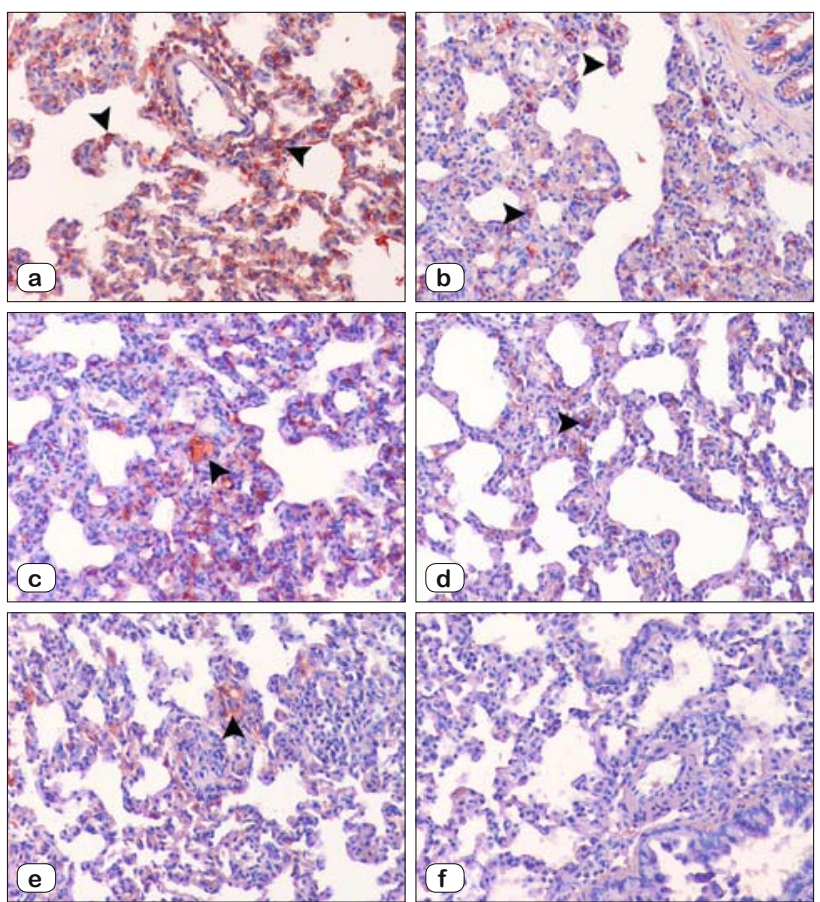

Fig. 5. Immunohistochemical expression of iNOS in all study groups (a, c, e - study group, b, d, f - treatment group). Immunoperoxidase technique, Harris hematoxyline counter staining, AEC as a chromogen, x20. a - Strong immunopositive reaction of iNOS in the HCL group. Cytoplasmic and membranous staining of the cells in the interalveoler septal tissue was represented (arrow heads), $b$ - Moderate immunopositive reaction of iNOS in $\mathrm{HCL}+\mathrm{LEF}$ group, intracytoplasmic staining in the thickened alveolar septum (arrow heads), $\mathrm{c}$ - Moderate İNOS immunoreactivity in FOR group (arrow head), $d$ - Weak immunohistochemical reaction in the interalveolar septal tissues (arrow head) of FOR+LEF group, $\mathrm{e}$ - Weak iNOS positive reaction in the interstitial cells in the interalveolar septal tissues of Sham group (arrow head), $f-$ There is no immunopositivive reaction of INOS in the SF+LEF group. 
prevalent in lung tissue (Fig. 4a). The histopathological scores for PICI, ASI, AED, AEX, and AHI were higher in the $\mathrm{HCl}$ group than in the sham group $(\mathrm{p}=0.001, \mathrm{p}=0.001, \mathrm{p}=0.001, \mathrm{p}<0.01$, and $\mathrm{p}=0.001$, respectively) (Fig. 3). All the scores in the FOR groups were increased compared to the sham group $(p=0.001)$. After FOR aspiration, moderate ASI was observed in the lung tissue (Fig. 4b). In the $\mathrm{HCl}+\mathrm{LEF}$ group, all the histopathological scores, except for AHI $(p>0.05)$, were lower than in the $\mathrm{HCl}$ group $(\mathrm{p}=0.001)$. There was a significant decrease in the PICI, ASI, AED, AEX, and AHI scores in the FOR+LEF group compared to the FOR group ( $p<0.01, p<0.01, p<0.05$, and $p<0.05$, respectively) (Fig. 3). There was no statistically significant change in any of the histopathological scores in the sham and $\mathrm{S}+\mathrm{LEF}$ groups. The lung tissue in the sham group showed a normal structure (Fig. 4d).

\section{Immunohistochemical results}

In the $\mathrm{HCl}$ group, strong iNOS-positive cells were observed in the interalveoler septal tissue (median $3+[3+/ 3+]$ ) (Fig. 4a). iNOSpositive cells were significantly lower in the $\mathrm{HCl}+\mathrm{LEF}$ (median $1+[0+/ 1+])($ Fig. 4b) and FOR +LEF groups (median $1+[0+/ 2+])$ (Fig. 4d) compared to the $\mathrm{HCl}$ (median $3+[3+/ 3+]$ ) (Fig. 4a) and FOR groups (median $2+[1+/ 3+]$ ) (Fig. 4 c). In the sham group, a weak iNOS-positive reaction (median $-/+[0+/ 1+]$ ) (median) was observed in the interstitial cells in the interalveolar septal tissues (Fig. 4e). There was no immunopositive reaction of iNOS in the $\mathrm{SF}+\mathrm{LEF}$ group (median $0+[0+/ 0+])$ (Fig. 4f).

\section{Discussion}

In this study, the pathogenesis of aspiration syndrome, which is a particularly significant problem in anesthesia and intensive care units, was evaluated in an experimental rat model. $\mathrm{HCl}$ aspiration of gastric contents and FOR, an important component of lung injury, was used in the experimental model. After $\mathrm{HCl}$ aspiration, a statistically significant increase was found in serum YKL-40 levels in parallel with lung injury. The increase in serum YKL-40 values after FOR aspiration was not statistically significant. LEF treatment was effective, especially in lowering the increased level of TBARS in acid aspiration-induced lung injury. Although there was no significant increase in serum YKL-40 levels in FOR aspiration-induced lung injury, TBARS levels, which were increased after lung injury, significantly decreased after the LEF treatment. LEF was effective in particular in reducing the expression of iNOS in tissue in the lung injury induced by $\mathrm{HCl}$ and $\mathrm{FOR}$ aspiration.

ALI is a diffuse form of heterogeneous lung injury, which develops due to primary (e.g., pneumonia) and secondary (e.g., pancreatitis) factors. It may cause life-threatening complications, such as ARDS (21). AP is one of the most important causes of primary lung damage. AP is common during anesthesia and intensive care and develops due to aspiration of gastric contents. Aspiration of gastric contents during the induction of anesthesia and recovery from anesthesia and aspiration of food during longterm enteral feeding in intensive care units give rise to serious complications (22). Although many studies have investigated the complex inflammatory mechanisms of ALI, there is no specific treatment that provides therapeutic efficacy $(23,25)$. Research is ongoing on reactive oxygen species (ROS), nitrogen species, and proinflammatory cytokines that contribute to the inflammatory process. Alveolar-capillary damage, leakage of protein-rich fluid into the interstitium and alveolar space, excessive release of cytokines, and neutrophil migration cause hypoxia and systemic damage in the acute phase of ALI (23). In our study, we observed a significant increase in PICI, ASI, AED, AEX, and AHI in lung tissue in the histopathological examination after $\mathrm{FOR}$ and $\mathrm{HCl}$ aspiration. This finding is similar to that reported in other working models, which demonstrated a comparable damage after gastric content aspiration $(20,24,25)$.

One of the most important mechanisms responsible for lung injury is a direct cell damage due to oxidation of the lipid component in the cell membrane caused by ROS, the production of which increases in response to activated macrophages, endothelial cells, and polymorphonuclear neutrophils (25). The degree of lipid peroxidation, which disrupts the permeability and the integrity of the membrane, is determined by TBARS levels in blood and tissue (26). Many experimental studies have used serum TBARS levels in the follow-up of inflammation, which forms as a result of tissue damage $(27,6)$. In an experimental ischemia-reperfusion study of rats, Yildiz et al. stated that serum TBARS levels are quite an effective marker in the determination of the severity of the oxidative stress that increases after injury (16). We found that serum TBARS levels increased in line with the histopathological findings of aspiration-induced lung injury. We observed a decrease in the serum levels of TBARS after the treatment with LEF. The findings highlight the importance of lipid peroxidation, especially in the damage that occurs in lung tissue after aspiration.

Many studies have demonstrated an increase in NO metabolites in body fluids in various models of ALI and ARDS $(28,29)$. NO is the inflammatory mediator synthesized from L-arginine, an amino acid (8) and peroxynitrite, which is formed by NO, thought to play an important role in the advancement of ALI (9). Studies have demonstrated that selective inhibition of iNOS decreases tissue damage $(11,30)$. In our study, we observed that immunohistochemical iNOS expression and lipid peroxidation were significantly increased in the $\mathrm{HCl}$ and $\mathrm{FOR}$ aspiration groups and that LEF treatment significantly decreased this expression.

Various rating systems are available for diagnosis of ALI. However, none are superior in disease follow up. New evaluation methods are required which show the type, degree, and severity of inflammation (9). Studies have used various biomarkers in epithelial fluid obtained from bronchoalveolar lavage, serum, and tissue to investigate lung inflammation $(31,32)$. Examples include inflammatory cytokines and molecules produced by epithelial and inflammatory cells, such as cellular growth factors, enzymes, and plasma-derived proteins (33-35). Endothelial and alveolar epithelial damage in ALI results in a systemic inflammatory response. (23). Much research is focused on identifying serum and tissue biomarkers in ALI that can be used to follow up inflammation. YKL-40 383 is a glycoprotein composed of amino acids. YKL-40 controls basic functions in mammalian cells, such as mitogenesis, differentiation, and extracellular matrix homeostasis. It is produced in many cells of the body, such as macrophages, neutrophils, chon- 
drocytes, fibroblasts, vascular smooth muscle, endothelial, hepatic stellate, colonic, and airway epithelial ductal cells, and serum levels of YKL-40 increase significantly at sites of tissue damage (36, 37). Recent studies reported that YKL-40 levels are increased in bronchial asthma and chronic obstructive pulmonary disease and that they can be used as a biomarker for these diseases (37-39). Guerra et al reported that YKL-40 is an indicator of reduced lung function and that it can be used as a biomarker in the monitoring of the pulmonary function of chronic cigarette smokers (41). Kim et al measured the level of YKL-40 in patients with pulmonary or pleural diseases (12). They found a higher level in patients with pneumonia compared to the control group and patients with pleural disease, asthma, or cancer. They stated that YKL-40 is a more valuable biomarker in patients with pneumonia than in patients with asthma (12). In our study, we found serum YKL-40 levels increased in lung injury occurring after the aspiration consistent with that reported in the literature.

LEF is an anti-inflammatory agent used in particular for the treatment of autoimmune diseases. It is thought to be effective in inhibiting proinflammatory cytokines by active metabolite A771726 (teriflunomide) $(42,16)$. Many studies have reported that the antiinflammatory and immunoregulatory effects of LEF suppress the formation of ROS and tumor necrosis factor induced by lipid peroxidation and nuclear factor-kappa B activation, respectively, both of which play an important role in inflammation $(18,19,42)$. In an intestinal ischemia-reperfusion study performed on rats, Yildiz et al demonstrated that LEF exhibited anti-inflammatory and antioxidant effects on damaged intestinal tissue (16). Similarly, in a renal ischemia/reperfusion study performed on rats, Karaman et al. demonstrated the efficacy of LEF in combatting oxidative damage following ischemia-induced ROS production in kidney (43).

In summary, the inhalation of gastric contents plays an important role in aspiration-induced lung damage. $\mathrm{HCl}$ is responsible for the majority of this damage. LEF therapy appears to be effective in combatting lung injury that develops secondary to aspiration. The current study can lay the groundwork for clinical studies.

\section{References}

1. Elpern EI, Scott MG, Petro L, Ries MH. Pulmonary aspiration in mechanically ventilated patients with tracheostomies. Chest 1994; 105 (2): 563-566.

2. Marik PE. Aspiration pneumonitis and aspiration pneumonia. N Engl J Med 2001; 344 (9): 665-671.

3. Bynum LJ, Pierce AK. Pulmonary aspiration of gastric contents. Am Rev Respir Dis 1976; 114 (6): 1129-1136

4. Greene S, Harris C, Singer J. Gastrointestinal decontamination of the poisoned patient. Pediatr Emerg Care 2008; 24 (3): 176-186.

5. Francis RCE, Schefold JC, Bercker $S$ et al. Acute respiratory failure after aspiration of activated charcoal with recurrent deposition and release from an intrapulmonary cavern. Intensive Care Med 2009; 35 (2): 360-363.

6. Valko M, Leibfritz D, Moncol J, Cronin M TD, Mazur M, Telser J. Free radicals and antioxidants in normal physiological functions and human disease. Int J Biochem cell Biol 2007; 39: 44-84.
7. Enkhbaatar P, Wang J, Saundera F et al. Mechanistic aspects of inducible nitric oxide synthase-induced lung injury in burn trauma. Burns 2011; 37 (4): 638-645.

8. Tasaka S, Amanya F, Hashimoto S, Ishizaka A. Roles of oxidants and redox signaling in the pathogenesis of acute respiratory distress syndrome. Antioxid Redox Signal 2008;10 (4): 739-753.

9. Boshier PR, Hanna GB, Marczin N. Exhaled nitric oxide as biomarker of acute lung injury: an unfulfilledd promise? J Breath Res 2013; 7 (1): 017118.

10. Güzel A,Güzel A, Günaydin $M$ et al. The role of iNOS inhibitors on lung injury induced by gastrointestinal decontamination agents aspiration. J Mol Histol 2012: 43 (3): 351-360.

11. Jian MY, Koizumi T, Kubo K. Effects of nitric oxide synthase inhibitor on acid aspiration-induced lung injury in rats. Pulm Pharmacol Ther 2005; 18 (1): 33-39.

12. Kim HR, Jun CD, Lee KS, Cho JH, Jeong ET, Yang SH, Lee YJ, Park DS. Levels of YKL-40 in pleural effusions and blood from patients with pulmonary or pleural disease. Cytokine 2012; 58 (3): 336-343.

13. Lee CG, Da Silva CA, Dela Cruz CS et al. Role of chitin/chitinaselike proteins in inflammation, tissue remodeling, and injury. Annu Rev Physiol 2011; 73: 479-501.

14. Chupp GL, Lee CG, Jarjour $\mathbf{N}$ et al. A chitinase-like protein in the lung and circulation of patients with severe asthma. N Engl J Med 2007; 357 (20): 2016-27.

15. Hector A, Kormann MS, Mack I et al. The chitinase-like protein YKL-40 modulates cystic fibrosis lung disease. PLoS One 2011; 6 (9): e24399.

16. Yildiz Y, Kose H, Cecen S, Ergin K, Demir EM, Serter M. Protective effects of Leflunamide on intestinal ischemia-reperfusion injury. Dig Dis Sci 2010; 55 (2): 245-252.

17. Zhang L, Qi Z, Wu D, Shan S, Ekberg H. Additive effects of leflunomide and tacrolimus in prevention of islet xenograft rejection. Scand J Immunol 2004; 59 (3): 255-260.

18. Yao HW, Li J, Chen JQ, Xu SY. Inhibitory effect of leflunomide on hepatic fibrosis induced by CCl4 in rats. Acta Pharmacol Sin 2004; 25 (7): 915-920.

19. Ozturk E, Demirbilek $S$, Begec $Z$ et al. Does leflunomide attenuate the sepsis-induced acute lung injury?. Pediatr Surg Int 2008; 24 (8): 899-905.

20. Takil A, Umuroglu T, Gogus YF, Eti Z, Yildizeli B, Ahiskali R. Histopathologic effects of lipid content of enteral solutions after pulmonary aspiration in rats. Nutrition 2003; 19 (7-8): 666-669.

21. Matthay MA, Ware LB, Zimmerman GA. The acute respiratory distress syndrome. J Clin Invest 2012; 122 (8): 2731-2740.

22. Tarrac SE. A description of intraoperative and postanesthesia complication rates. J Perianesth Nurs 2006; 21 (2): 88-96.

23. Girard TD, Bernard GR. Mechanical ventilation in ARDS: a stateof-the-art review. Chest 2007; 131 (3): 921-929.

24. Umuroğlu T, Takil A, Irmak $P$ et al. Effects of multiple pulmonary aspirations of enteral solutions on lung tissue damage. Clin Nutr 2006; 25 (1): 45-50.

25. Ray G, Husain SA. Oxidants, antioxidants and carcinogenesis. Indian J Exp Biol 2002; 40 (11): 1213-1232.

26. Guo R, Ward PA. Role of oxidants in lung injury during sepis. Antioxid Redox Signal 2007; 9 (11): 1991-2002. 
27. Yousef MI , Omar SA, El-Guendi MI, Abdelmegid LA. Potential protective effects of quercetin and curcumin on paracetamol-induced histological changes, oxidative stress, impaired liver and kidney functions and haematotoxicity in rat. Food Chem Toxicol 2010; 48 (11): 3246-3261.

28. Lakshminrusimha S, Suresh MV, Knight PR et al. Role of pulmonary artery reactivity and nitric oxide in injury and inflammation following lung contusion. Shock 2013; 39 (3): 278-285.

29. Sittipunt C, Steinberg KP, Ruzinski JT et al. Nitric oxide and nitrotyrosine in the lungs of patients with acute respiratory distress syndrome. Am J Respir Crit Care Med 2001; 163 (2): 503-510.

30. Malaviya R, Venosa A, Hall $L$ et al. Attenuation of acute nitrogen mustard-induced lung injury, inflammation and fibrogenesis by a nitric oxide synthase inhibitor. Toxicol Appl Pharmacol 2012; 265 (3): 279-291.

31. Choi, J, Hoffman LA, Rodway GW, Sethi JM. Markers of lung disease in exhaled breath: nitric oxide. Biol Res Nurs 2006; 7 (4): 241-255.

32. Dickens JA, Lomas DA. CC-16 as a biomarker in chronic obstructive pulmonary disease. COPD 2012; 9 (5): 574-575.

33. Ishizaka A, Matsuda T, Albertine KH et al. Elevation of KL-6, a lung epithelial cell marker, in plasma and epithelial lining fluid in acute respiratory distress syndrome. Am J Physiol Lung Cell Mol Physiol 2004; 286 (6): L1088-L1094.

34. Parsons PE, Eisner MD, Thompson BT et al. Lower tidal volume ventilation and plasma cytokine markers of inflammation in patients with acute lung injury. Crit Care Med 2005; 33 (1): 1-6; discussion 230-232.

35. Roxburgh CS, McMillan DC. The Role of systemic inflammatory response in predicting survival in patients with primary operable cancer. Future Oncol 2010; 6 (1): 149-163.
36. Badariotti F, Kypriotou M, Lelong $\mathbf{C}$ et al. The phylogenetically conserved molluscan chitinase-like protein 1 ( $\mathrm{Cg}$-Clp1), homologuc of human HC-gp39, stimulates proliferation and regulates synthesis of extracellular matrix components of mammalian chondrocytes. J Biol Chem 2006; 281 (40): 29583-29596.

37. Lee CG, Hartl D, Lee GR et al. Role of breast regression protein 39 (BRP-39)-chitinase 3-like 1 in Th2 and il-13-induced tissue responses and apoptosis. J Exp Med 2009; 206 (5): 1149-1166.

38. Sakazaki Y, Hoshino T, Takei $\mathbf{S}$ et al. Overexpression of chitinase 3-like 1/YKL-40 in lung-specific IL-8-transgenic mice, smokers and COPD. Plos One 2011; 6 (9): e24177.

39. Lee CG, Dela Cruz CS, Ma B et al. Chitinase-like proteins in lung injury, repair, and metastasis. Proc Am Thorac Soc 2012; 9 (2): 57-61.

40. Gumus A, Kayhan S, Cinarka $\mathbf{H}$ et al. High serum YKL-40 level in patients with COPD is related to hypoxemia and disease severity. Tohoku J Exp Med 2013; 229 (2): 163-170.

41. Guerra S, Halonen M, Sherrill DL et al. The relation of circulating YKL-40 to levels and decline of lung function in adult life. Respir Med 2013. doi:pii: S0954-6111(13)00266-7.

42. Karaman A, Iraz M, Kirimlioglu H, Karadag N, Tas E, Fadillioglu E. Hepatic damage in biliary-obstructed rats is ameliorated by leflunomide treatment. Pediatr Surg Int 2006; 22 (9): 701-708.

43. Karaman A, Turkmen E, Gursul C, Tas E, Fadillioglu E. Prevention of renal ischemia/reperfusion-induced injury in rats by leflunomide. Int J Urol 2006; 13 (11): 1434-1441.

Received October 30, 2013. Accepted November 12, 2013. 